\title{
Survey of Prolonged Mechanical Ventilation in Intensive Care Units in Mainland China
}

\author{
Jie Li MSc, RRT-NPS RRT-ACCS, Qing Yuan Zhan MD, and Chen Wang MD, PhD
}

INTRODUCTION: In mainland China, there are no special care centers (long-term acute care, weaning, chronic care facilities) for patients requiring prolonged mechanical ventilation (PMV). Our goal was to characterize the prevalence and outcome of patients undergoing PMV in Chinese intensive care units (ICUs). METHODS: A prospective 1-d prevalence study was performed at 55 ICUs, with 28-d follow-up. RESULTS: On the observation day, 622 adult patients occupied ICU beds. Enrollment criteria were met by 302 subjects receiving invasive mechanical ventilation, of which $109(36.1 \%)$ had received ventilation for more than $21 \mathrm{~d}$ (median 51, 21-3,419), which was defined as PMV. During the following $28 \mathrm{~d}$, another 45 subjects were classified as receiving PMV, but only 5\% (3/58) of the subjects who were newly admitted to the ICU on the study day received PMV. Thirty-six (22.9\%) of the 157 subjects receiving PMV were weaned, and 81 (51.6\%) continued ventilation in the ICU. In the logistic regression analysis, age $>74$ y (odds ratio $=2.78,95 \%$ CI 1.05-7.40, $P=.041$ ) and chronic congestive heart failure (odds ratio $=12.23,95 \%$ CI 1.48 $101.05, P=.020)$ were associated with failure to wean in $28 \mathrm{~d}$, while acute respiratory distress syndrome (ARDS) as the reason for mechanical ventilation (odds ratio $=0.14,95 \%$ CI $0.04-0.52$, $P=.003$ ) was associated with successful weaning. CONCLUSION: The number of subjects receiving PMV was surprisingly high in this cross-section of Chinese ICUs. In the following 28 ICU days, only a small proportion of these subjects were weaned. Age and chronic heart dysfunction were high risk factors for weaning failure. Key words: invasive mechanical ventilation; prolonged mechanical ventilation; weaning; intensive care unit. [Respir Care 2016;61(9):1224-1231. (C) 2016 Daedalus Enterprises]

\section{Introduction}

As medical technologies are developing over time, more patients are surviving episodes of critical illness. How-

\footnotetext{
Ms Li is affiliated with the Department of Cardiopulmonary Sciences, Division of Respiratory Care, Rush University Medical Center, Chicago, Illinois. Dr Zhan is affiliated with the ICU, China-Japan Friendship Hospital, Beijing, People's Republic of China. Dr Wang is affiliated with the China-Japan Friendship Hospital, Beijing, People's Republic of China.

On behalf of the Chinese Prolonged Mechanical Ventilation study group.

The authors have disclosed no conflicts of interest.

Correspondence: Chen Wang MD, China-Japan Friendship Hospital, No. 2 Yinghuayuan Dong Street, Beijing 100029, PR China. E-mail: cyhrt@sina.cn
}

DOI: $10.4187 /$ respcare.04295 ever, some patients cannot recover to live independently and require use of medical equipment, such as mechanical ventilators. When a patient requires at least $6 \mathrm{~h} / \mathrm{d}$ of mechanical ventilation for $\geq 21$ consecutive days, this is defined as prolonged mechanical ventilation (PMV). ${ }^{1}$ A $32-$ bed intensive care unit (ICU) in southern Brazil reported that 42 of $453(9.3 \%)$ patients received PMV in half a year. $^{2}$ While PMV incidence was 6.3 per 100 ventilated ICU admissions from 2002 to 2006 in the United Kingdom, ${ }^{3}$ in Taiwan, the PMV rate fell from 94.3 to 89.38 per 100,000 persons from 2004 to $2007 .{ }^{4}$ In the United States, a population-based study found that the incidence of tracheostomy for PMV was 24.2 per 100,000 people in 2002, and this rate had increased by nearly $200 \%$ from the previous decade. ${ }^{5}$ Zilberberg and colleagues estimated that, based on growth trends between 1993 and 2005, the number of patients receiving PMV is expected to double between 2000 and 2020, from 252,577 to 605,898.6 From 2004 to 2009, a population-based co- 
hort study in 5 states showed that $5.5 \%$ of ICU patients needed PMV. ${ }^{7}$

With prolonged length of critical and acute care hospital stays, patients receiving PMV consume a disproportionate share of ICU resources, with median hospital costs ranging from 3-4 times the cost of short-term ventilation in acute care hospitals. ${ }^{8}$ This prolonged care also accounts for $29.1 \%$ of the general ICU bed days. ${ }^{4}$ In 2005, Medicare-eligible patients who required PMV ranked third in summative in-patient charges by diagnostic groups and first in charges per patient. ${ }^{9}$ Despite receiving such a high level of care, $29-49 \%$ of PMV patients died in the hospital, ${ }^{10,11}$ only $19 \%$ could be discharged home, ${ }^{10}$ and $<50 \%$ of PMV hospital survivors survived more than $1 \mathrm{y} \cdot{ }^{3,10-14}$ Compared with withdrawal of ventilation, providing PMV to the basecase patient costs $\$ 55,460$ per life-year gained and $\$ 82,411$ per quality-adjusted life-year gained. ${ }^{9}$ As a high-cost population, patients who receive PMV should be a priority focus for hospital managers to control daily expenditures, and alternative care venues should be considered other than the ICU. Step-down and special units, such as weaning centers, long-term acute care hospitals, and nursing facilities in America, ${ }^{13,15}$ respiratory care centers and wards in Taiwan, ${ }^{14,16}$ and respiratory ICUs in Europe ${ }^{3,17}$ have been established to treat patients who require PMV in a more cost-effective manner.

However, the prevalence of PMV and the venues to treat them in mainland China have never been reported. The aim of this study was to establish the prevalence of PMV, to report characteristics and 28-d outcomes of a PMV cohort in 55 ICUs within teaching hospitals across mainland China, and to explore the factors that affect the weaning success of patients who require PMV.

\section{Methods}

\section{Study Subjects}

Inclusion criteria were subjects who received mechanical ventilation via endotracheal intubation or tracheotomy in the ICU at 8 AM, July 10, 2007 and subjects admitted to the ICU between 8 AM, July 10 and 8 Am, July 11, 2007. Exclusion criteria were patients younger than $18 \mathrm{y}$ of age.

\section{Study Criteria}

Prolonged mechanical ventilation was defined as the need for $\geq 21$ consecutive days of mechanical ventilation for $\geq 6 \mathrm{~h} / \mathrm{d}$. Successful weaning was defined as off the ventilator for 7 consecutive d. Failed weaning was classified as subjects still alive who continued to need ventilation.

\section{QUICK LOOK}

\section{Current knowledge}

Prolonged mechanical ventilation (PMV) defined as at least $6 \mathrm{~h} / \mathrm{d}$ of mechanical ventilation for $\geq 21$ consecutive days is a global difficulty. Patients requiring PMV consume a disproportionate share of ICU resources, with greater hospital costs in acute care hospitals, and utilize significantly more ICU bed days than other patients. However, the prevalence and characteristics of patients requiring PMV in mainland China have never been reported.

\section{What this paper contributes to our knowledge}

The present observational study was conducted in 55 leading ICUs in mainland China. We found that more than one-fifth of ICU beds were occupied by ventilatordependent patients for a long period of time, taking up a significant proportion of ICU resources but with poor weaning outcomes. We also identified high risk factors for weaning failure.

\section{Study Design}

The study was approved by the institutional review board of Beijing Chaoyang Hospital. The primary research site and data-coordinating center was Beijing Chaoyang Hospital, which produced data collection forms and the operations manual. Fifty-five ICUs in teaching hospitals across mainland China participated in the survey and formed the Chinese Prolonged Mechanical Ventilation group. At each site, the ICU supervisor was in charge of the study, and a physician was appointed to enroll subjects, complete case report forms, and to complete subject follow-up at $28 \mathrm{~d}$. The initial study day was July 10, 2007, and all enrolled subjects received follow-up at $28 \mathrm{~d}$, unless discharged from the ICU without the need for ventilation or upon the patient's death.

Information collected included: (1) facility information: ICU type, number of beds, doctors, nurses, and other medical staff on both day and night shifts; (2) subjects' demographic information: age, sex, smoking history and premorbid functional status (Zubrod score: 0 , fully active; 1 , restricted in strenuous activity; 2 , ambulatory, self-care, no work; 3 , bedridden $>50 \%$ of time, limited self care; 4 , bedridden, no self-care) ${ }^{18}$; (3) ICU admitting diagnosis and the primary reason for mechanical ventilation; (4) comorbidities; (5) artificial airway type and the tracheotomy time; (6) the ventilator mode and settings on the study day; (7) complications associated with mechanical ventilation during the following $28 \mathrm{~d}$ : ventilator-associated pneumo- 


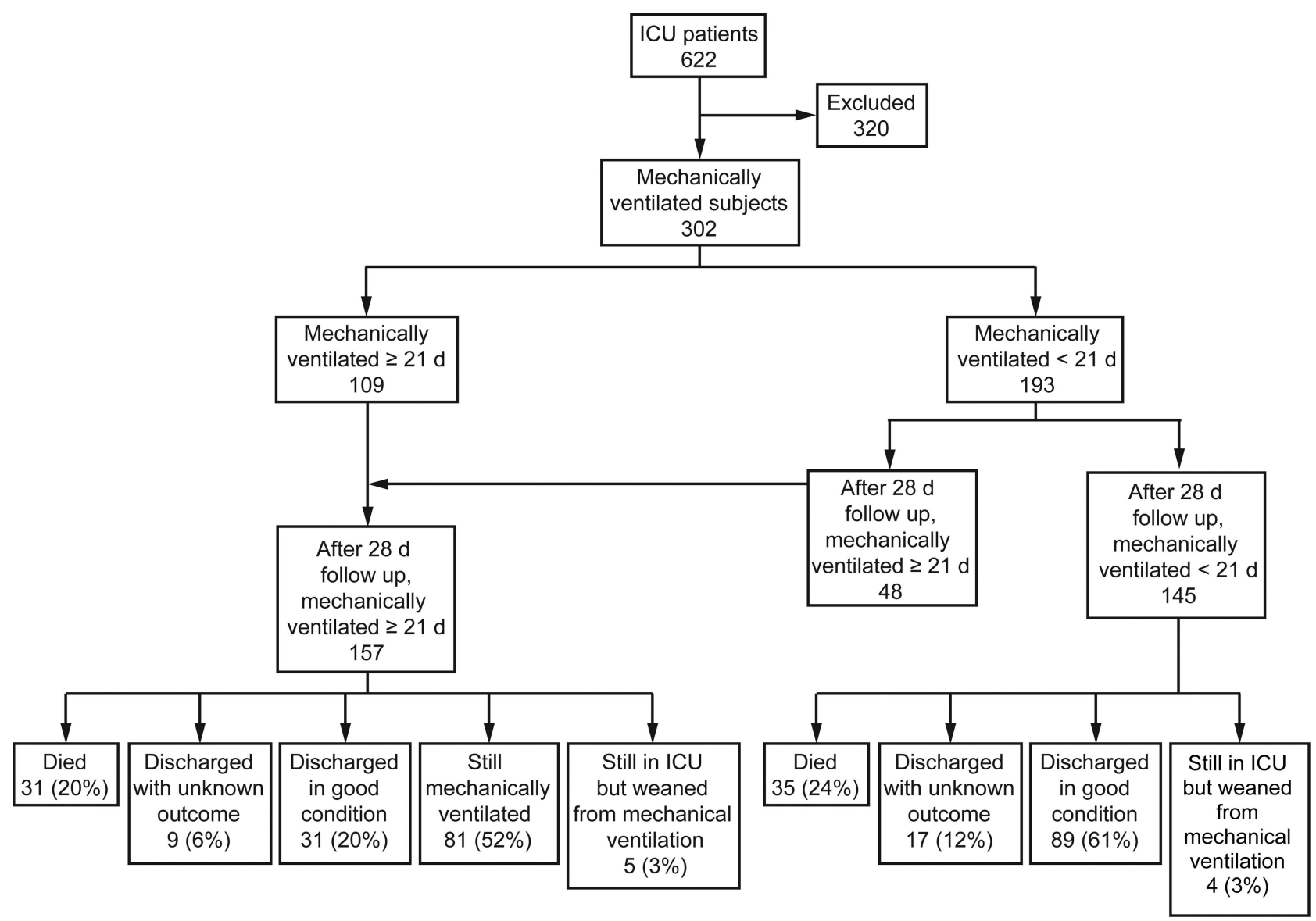

Fig. 1. Flow chart.

nia (VAP), pneumothorax, and subcutaneous emphysema; and (8) ICU outcome in the following $28 \mathrm{~d}$.

Diagnosis criteria for VAP were ${ }^{19}$ : a new and persistent $(>48 \mathrm{~h}$ ) or a progressive radiographic infiltrate plus 2 of the following: temperature of $>38^{\circ} \mathrm{C}$ or $<36^{\circ} \mathrm{C}$, blood leukocyte count of $>10,000$ cells $/ \mathrm{mL}$ or $<5,000$ cells $/ \mathrm{mL}$, purulent tracheal secretions, and gas exchange degradation.

\section{Statistical Analysis}

Population-weighted descriptive statistics were calculated (means, standard deviations, median, tabulations, and proptions) for all questions. Kolmogorov-Smirnov statistical tests were used to determine the normality of distribution for the considered variables. Continuous variables between the 2 groups of subjects are expressed as mean (SD or SEM) or median (minimum to maximum) and compared with the parametric (Student $t$ test) or nonparametric (2-independent samples tests, Mann-Whitney U) test based on distribution of variables, whereas differences in categorical variables were assessed using the chi-square test. Binary stepwise logistic regression analyses were used to explore relationships between successfully weaned and failed weaning subjects undergoing PMV. A $P$ value of $<.05$ was considered statistically significant for all tests. Data analysis was conducted with SPSS statistical software (SPSS 16.0 for Windows; SPSS; Chicago, Illinois).

\section{Results}

This prospective prevalence study was performed throughout 55 ICUs within 51 teaching hospitals in 26 major cities, such as Beijing, Shanghai, Guangzhou, and others, representing 780 beds, 377 physicians and 503 nurses on the day shift, and 114 physicians and 317 nurses on the night shift.

\section{PMV Prevalence}

At 8 Am on July 10, 2007, 536 adult patients occupied ICU beds, with 242 subjects receiving invasive ventilation. Of those, $109(45.0 \%, 109 / 242)$ subjects had required ventilation for more than $21 \mathrm{~d}$ (median $51 \mathrm{~d}$, ranging from 21-3,419 d) in ICU (Fig. 1). Of the remaining 133 subjects, 45 were classified as requiring PMV 28 d later. From 


\section{Survey of Prolonged Mechanical Ventilation in the ICU}

8 Am July 10 to 8 Am July 11,86 subjects were admitted to the ICUs, with 60 subjects receiving invasive mechanical ventilation. Two of these subjects had already received ventilation outside of the ICU for $1 \mathrm{~d}$ and $5 \mathrm{~d}$, respectively. The total duration of invasive ventilation for the 2 subjects was $4 \mathrm{~d}$ and $12 \mathrm{~d}$. Of the 58 subjects newly receiving invasive ventilation, only $3(5.2 \%, 3 / 58)$ needed PMV at the end of the following $28 \mathrm{~d}$ (Fig. 1).

\section{PMV Subjects' Characteristics}

The characteristics and data for the 157 subjects requiring PMV are shown in Table 1. Multiple comorbidities involving the respiratory, cardiovascular, and neuromuscular systems were noted with an average of 1.85 major comorbidities in each subject. Hypertension was the most common disease charted (45.2\%) followed by COPD $(33.7 \%)$. Acute respiratory failure was the main reason for mechanical ventilation: $41(26.1 \%)$ subjects for nonaspirated pneumonia, 35 (22.3\%) for exacerbation of COPD, and $30(19.1 \%)$ for ARDS. Some subjects might have had more than one reason for mechanical ventilation. On the study day, SIMV+PSV (synchronized intermittent mandatory ventilation + pressure support ventilation) was the most popular ventilation mode $(45.2 \%)$, and only $26 \%$ of subjects were supported with PSV/CPAP. During the following $28 \mathrm{~d}, 37.6 \%$ of subjects developed VAP, and $1.9 \%$ had pneumothorax. Eight subjects received paralytics and 14 received high-dose corticosteroids. The time to tracheotomy for 131 subjects was 13.5 (median, ranging from 5-57 d) d. Of the 157 subjects receiving PMV, 9 had a previous diagnosis of neuromuscular diseases and 6 of these had already received ventilation for more than $1 \mathrm{y}$. The 6 subjects' invasive mechanical ventilation duration were $518,815,1,108,2,460,3,402$, and 3,419 d respectively; 5 subjects had amyotrophic lateral sclerosis, and 1 subject had a motor neuron disease. Another 11 subjects had received ventilation for more than $1 \mathrm{y}$.

\section{Subjects' 28-d Outcome}

Of the 157 subjects enrolled, $31(19.7 \%)$ died in the ICU, $9(5.7 \%)$ were discharged from the hospital at the request of the subjects or their surrogates with unknown outcomes, $36(22.9 \%)$ were weaned, and the remaining 81 continued ventilation in the ICU. Of the 36 subjects who were weaned, 31 were discharged from the ICU in good condition, and 5 were still in the ICU.

After $28 \mathrm{~d}, 81$ subjects required assisted ventilation in the ICU. We excluded the 20 subjects who were described above (11 receiving more than $1 \mathrm{y}$ of ventilation and 9 subjects with neuromuscular disease) from the analysis, because it was unlikely that they could be weaned. ${ }^{16} \mathrm{We}$ compared the remaining 61 subjects requiring assisted ven- tilation with the 36 successfully weaned subjects. The weaned subjects were younger [62.5 (median, ranging from $19-85$ ) vs 78 (median, ranging from $18-103$ ), $P<.001$ ], and had a higher ratio of good premorbid functional status with a Zubrod score $0-2(72.2 \%$ vs $52.5 \%, P=.055)$. Moreover, they had fewer comorbidities, especially chronic congestive heart failure $(2.8 \%$ vs $29.5 \%, P=.001)$ and COPD (13.9\% vs $44.3 \%, P=.002)$, a smaller proportion of them required ventilation for COPD exacerbation (13.9\% vs $36.1 \%, P=.019)$ while more required it for ARDS $(38.9 \%$ vs $8.2 \%, P<.001)$. For the subjects whose ventilation duration was longer than $90 \mathrm{~d}$, the proportion was much smaller in successfully weaned subjects $(11.1 \%$ vs $29.5 \%, P=.037$ ) (Table 2). There was no difference between the 2 groups in APACHE II scores, sex, smoking history, or facility information, including the ratio of medical staff to subjects during day and night shifts.

In the logistic regression analysis, age more than $74 \mathrm{y}$ $($ Odds Ratio $=2.78,95 \% \mathrm{CI}[\mathrm{CI}] 1.05-7.40, P=.041)$ and COPD (Odds Ratio $=12.23,95 \%$ CI $1.48-101.05$, $P=.02$ ) were associated with failure to wean in $28 \mathrm{~d}$, while ARDS as the reason for mechanical ventilation (Odds Ratio $=0.14,95 \%$ CI $0.04-0.52, P=.003)$ was associated with successful weaning.

\section{Discussion}

This was the first study to report the prevalence and characteristics of patients requiring PMV in mainland China. The 55 ICUs that completed surveys were located in teaching hospitals with advanced equipment and highly skilled and experienced medical personnel; critically ill patients might be more likely to survive in such an environment. Moreover, these ICUs were prone to accept severely ill patients and difficult-to-wean patients transferred from community hospitals. This may contribute to the high prevalence of PMV in our survey. In fact, if we exclude the subjects who had already undergone PMV before the day of the survey, the proportion of new subjects was only $5.2 \%$, similar to the incidence rate in the United States $(3-7 \%)^{1,7}$ and the United Kingdom $(4.4 \%) .^{3}$

Once patients become classified as requiring PMV, it is very hard for them to be transferred to other venues in mainland China. In our study, no subject receiving invasive ventilation could be transferred out of the ICU, and this inability to transition patients out of the ICU resulted in longer ICU stays of $52 \mathrm{~d}$ (median). Results from the European, ${ }^{3,20-22}$ American ${ }^{8,13,15}$ and Taiwan ${ }^{14,16}$ case series would suggest that patients whose primary problem is ventilatory dependence can be managed in less intensive step down units, thereby reducing costs and facilitating a focus on ventilatory care and rehabilitation. Because the transfer policy of "failure to wean" patients was adopted, ${ }^{16} \mathrm{ICU}$ stay for subjects undergoing PMV decreased from 


\section{Survey of Prolonged Mechanical Ventilation in the ICU}

Table 1. Characteristics of Subjects Who Required PMV

\begin{tabular}{|c|c|c|c|}
\hline \multirow{2}{*}{ Subject characteristics } & \multicolumn{2}{|c|}{ ProVent study ${ }^{23}$} & \multirow{2}{*}{ Present study } \\
\hline & Development & Validation & \\
\hline$n$ & 200 & 100 & 157 \\
\hline Age, y & $58(42-69)$ & $57(44-66)$ & $74(18-103)$ \\
\hline Sex, male $(\%)$ & $120(60)$ & $49(49)$ & $103(66)$ \\
\hline APACHE II score when admitted to ICU & $20.6 \pm 7.3$ & $25.3 \pm 6.8$ & $20.1 \pm 7.4$ \\
\hline Good pre-morbid functional status (Zubrod score $0-2), n(\%)$ & $143(82)$ & $60(76)$ & $82(52)$ \\
\hline Smoking, $n(\%)$ & & & $54(34.4)$ \\
\hline Charlson Comorbidity Index Score, mean \pm SD & $2.7 \pm 2.2$ & $3.1 \pm 2.3$ & $2.8 \pm 1.6$ \\
\hline \multicolumn{4}{|l|}{ Co-morbidities, $n(\%)$} \\
\hline Respiratory & $22(11)$ & $14(14)$ & $72(46)$ \\
\hline COPD & & & $53(34)$ \\
\hline Asthma & & & $3(2)$ \\
\hline Interstitial lung disease, pulmonary fibrosis & & & $3(2)$ \\
\hline Pulmonary tuberculosis & & & $9(6)$ \\
\hline $\begin{array}{l}\text { Others (bronchiectasis, pulmonary embolism, obstructive sleep } \\
\text { apnea syndrome) }\end{array}$ & & & $4(3)$ \\
\hline Cardiovascular & & & 159 \\
\hline Hypertension & & & $71(45)$ \\
\hline Chronic congestive heart failure & $30(15)$ & $15(15)$ & $36(23)$ \\
\hline Coronary artery disease & $16(8)$ & $7(7)$ & $18(12)$ \\
\hline Cardiac arrhythmia & & & $31(20)$ \\
\hline Others (rheumatic heart disease, aortic coarctation) & & & $3(2)$ \\
\hline Neurologic & & & $59(38)$ \\
\hline Cerebral infarction & & & $26(17)$ \\
\hline Cerebral hemorrhage & & & $9(6)$ \\
\hline $\begin{array}{l}\text { Neuromuscular disease (amyotrophic lateral sclerosis, motor neuron } \\
\text { diseases, Guillain-Barré) }\end{array}$ & & & $11(7)$ \\
\hline Parkinson & & & $6(4)$ \\
\hline $\begin{array}{l}\text { Others (vascular dementia, cerebral arteriosclerosis, epilepsia, } \\
\text { hypophysoma) }\end{array}$ & & & $7(5)$ \\
\hline Diabetes mellitus & & & $42(27)$ \\
\hline Hypothyroidism & & & $2(1)$ \\
\hline Renal insufficiency/failure & & & $12(8)$ \\
\hline Malignant tumor & & & $12(8)$ \\
\hline Hospital surgery, $n(\%)$ & & & $50(32)$ \\
\hline Emergency & & & $29(19)$ \\
\hline Schedule & & & $21(13)$ \\
\hline \multicolumn{4}{|l|}{ Causes due to mechanical ventilation, $n(\%)$} \\
\hline Acute respiratory failure & & & $143(91)$ \\
\hline ARDS & $10(5)$ & $5(5)$ & $30(19)$ \\
\hline Acute cardiogenic pulmonary edema & $2(1)$ & $4(4)$ & $12(8)$ \\
\hline Pneumonia (nonaspiration) & $13(7)$ & $14(14)$ & $41(26)$ \\
\hline Aspiration & & & $16(10)$ \\
\hline Exacerbation of COPD & $4(2)$ & $2(2)$ & $35(22)$ \\
\hline Trauma & $32(16)$ & $10(10)$ & $9(6)$ \\
\hline Head trauma with or without multiple injuries & $4(2)$ & 0 & $4(3)$ \\
\hline Chest trauma with flail chest or hemopneumothorax & & & $5(3)$ \\
\hline Sepsis & & & $19(12)$ \\
\hline Cardiopulmonary resuscitation & $8(4)$ & $7(7)$ & $14(9)$ \\
\hline Coma & & & $\begin{array}{l}30(19) \\
\text { (continued) }\end{array}$ \\
\hline
\end{tabular}


Table 1. Continued

\begin{tabular}{|c|c|c|c|}
\hline \multirow{2}{*}{ Subject characteristics } & \multicolumn{2}{|c|}{ ProVent study ${ }^{23}$} & \multirow{2}{*}{ Present study } \\
\hline & Development & Validation & \\
\hline Neurologic diseases & $8(4)$ & 0 & $36(23)$ \\
\hline New cerebrovascular accident or intracranial hemorrhage & & & $22(14)$ \\
\hline New onset or progression of neuromuscular diseases & & & $11(7)$ \\
\hline Others & & & $3(2)$ \\
\hline Respiratory support after surgery & $54(27)$ & $26(26)$ & $17(11)$ \\
\hline Cardiovascular & $20(10)$ & $5(5)$ & $2(1)$ \\
\hline Thoracic & $13(7)$ & $6(6)$ & $2(1)$ \\
\hline Gastrointestinal & $13(7)$ & $13(13)$ & $8(5)$ \\
\hline Neurological & $8(4)$ & $2(2)$ & $5(3)$ \\
\hline Paralysis, $n(\%)$ & & & $8(5)$ \\
\hline High dose of corticosteroid, $n(\%)$ & & & $14(9)$ \\
\hline Complications of invasive ventilation, $n(\%)$ & & & $62(40)$ \\
\hline Pneumothorax & & & $3(2)$ \\
\hline VAP & & & $59(38)$ \\
\hline Tracheostomy, $n(\%)$ & $167(84)$ & $77(77)$ & $135(86)$ \\
\hline Time to tracheotomy, $\mathrm{d}$ & $17(12-22)$ & $19(12-26)$ & $14(5-57)$ \\
\hline Mechanical ventilation duration, $\mathrm{d}$ & $35(26-51)$ & $35(27-54)$ & $51(21-3494)$ \\
\hline ICU stay, $d$ & $37(28-52)$ & $36(30-54)$ & $52(14-3494)$ \\
\hline \multicolumn{4}{|l|}{$\begin{array}{l}\text { ARDS }=\text { acute respiratory distress syndrome } \\
\text { APACHE = Acute Physiology and Chronic Health Evaluation } \\
\text { ICU }=\text { intensive care unit } \\
\text { VAP = ventilator-associated pneumonia }\end{array}$} \\
\hline
\end{tabular}

$55.7 \pm 92.8$ to $21.4 \pm 12.7 \mathrm{~d}$ in Taiwan ${ }^{16}$. Similarly, ICU stays were $25-37 \mathrm{~d}$ in America ${ }^{11,15,23}$ and $26 \mathrm{~d}$ in Europe. ${ }^{21}$ However, currently no special unit for patients requiring PMV exists in mainland China. Only 22.9\% of subjects were weaned from mechanical ventilation in our study, compared with the high ratio of successful weaning (43-53\%) in American hospitals, ${ }^{23} 54.1 \%$ in the 23 American weaning centers, ${ }^{15}$ and $64.2 \%$ in Taiwan weaning centers. ${ }^{14}$ It might be due to lack of trained multidisciplinary professionals, such as respiratory therapists, as shown in our previous study. ${ }^{24}$

It is very important to identify the possibility of successful weaning in patients requiring PMV. Dermot Frengley et $\mathrm{al}^{25}$ recently found that weaning success decreased with age, higher comorbidity burden, and more-severe illness, which was in agreement with our findings. We also found that chronic congestive heart failure was a significant predictor of weaning failure. Weaning from positivepressure ventilation increases venous return and left ventricular afterload. Such increases may not be tolerated by patients with compromised heart function, which becomes the cause or a cofactor of weaning failure, ${ }^{26}$ described as "weaning-induced cardiovascular compromise."26,27

One limitation of our study was that we did not acquire more comprehensive information to decide whether subjects could be transferred out of the ICU or not. Additionally, we only followed the subjects for $28 \mathrm{~d}$ in the ICU, and we did not collect subject data on the 14th or 21st day of mechanical ventilation. Consequently, we could not use the prognostic model proposed by Carson et $\mathrm{al}^{23}$ to predict our subjects' 1-y mortality. ${ }^{11}$ However, a comparison of subject characteristics is shown in table 1. Also, despite the small sample size and the design of our study, the risk factors for weaning that it revealed are consistent with current evidence; a follow-up study with a larger sample size is needed to verify our findings. The other limitation was that we did not investigate the actual reason why subjects were not transferred out of ICU. Because Chinese medical insurance reimbursement, environment, and systems are different from those in western society, future studies are needed to understand the benefits and opportunities to manage patients requiring PMV outside of the ICU environment. We are also aware that our study was performed 8 years ago, but the result is still valid, because no weaning center or specific chronic care facility has been established in mainland China as of the publication date of this paper.

\section{Conclusion}

The ratio of subjects requiring PMV was surprisingly high in the Chinese ICUs surveyed, with the majority of these subjects occupying ICU beds throughout their course of ventilation, using a disproportionate amount of ICU 
Table 2. Comparison Between Successful and Failed Weaning PMV Subjects

\begin{tabular}{|c|c|c|c|c|}
\hline & Wean failure & Wean success & $\begin{array}{l}\text { Died/discharged } \\
\text { with unknown } \\
\text { outcome }\end{array}$ & $\begin{array}{c}\text { Neuromuscular } \\
\text { disease/mechanical } \\
\text { ventilation }>1 \mathrm{y}\end{array}$ \\
\hline$n$ & 61 & 36 & 40 & 20 \\
\hline Age & $78(18-103)$ & $62.5(19-85)$ & $77(24-88)$ & $67.5(31-86)$ \\
\hline Female/male sex, $\%$ & $29.5 / 70.5$ & $33.3 / 66.7$ & $40 / 60$ & $40 / 60$ \\
\hline APACHE II score when admitted to ICU & $21(6-38)$ & $18(6-44)$ & $19(6-45)$ & $18(9-29)$ \\
\hline "Good" pre-morbid functional status (Zubrod score 0-2) & $32(52.5)$ & $26(72.2)$ & $20(50)$ & $4(20)$ \\
\hline Smoking, $\%$ & 37.7 & 33.3 & 30 & 35 \\
\hline \multicolumn{5}{|l|}{ Co-morbidities, $n(\%)$} \\
\hline Chronic congestive heart failure & $18(29.5)$ & $1(2.8)$ & $13(33)$ & $4(20)$ \\
\hline COPD & $27(44.3)$ & $5(13.9)$ & $7(17.5)$ & $4(20)$ \\
\hline Charlson comorbidity index & $2.95 \pm 1.55$ & $2.64 \pm 1.57$ & & \\
\hline Hospital surgery, $n(\%)$ & $17(22.7)$ & $16(38.1)$ & $17(42.5)$ & $3(15)$ \\
\hline \multicolumn{5}{|l|}{ Causes due to acute respiratory failure } \\
\hline ARDS & $5(8.2)$ & $14(38.9)$ & $11(27.5)$ & 0 \\
\hline Trauma & $1(1.6)$ & $5(13.9)$ & $2(5)$ & $1(5)$ \\
\hline COPD exacerbation & $22(36.1)$ & $5(13.9)$ & $5(12.5)$ & $4(20)$ \\
\hline High dose of corticosteroid & $3(4.9)$ & $7(19.4)$ & $3(7.5)$ & $1(5)$ \\
\hline Paralysis, $n(\%)$ & $1(1.6)$ & $3(8.3)$ & $4(10)$ & 0 \\
\hline Complications of invasive ventilation, $n(\%)$ & $27(44.3)$ & $11(30.6)$ & $17(42.5)$ & $7(35)$ \\
\hline Pneumothorax & 0 & $1(2.4)$ & $2(5)$ & 0 \\
\hline VAP & $26(42.6)$ & $11(30.6)$ & $15(37.5)$ & $7(35)$ \\
\hline Time to tracheotomy, $\mathrm{d}$ & $11(8-43)$ & $27(10-31)$ & $16(5-57)$ & \\
\hline ICU stay, $\mathrm{d}$ & $55(28-357)$ & $41.5(21-1015)$ & $39(14-220)$ & $663(62-3494)$ \\
\hline Mechanical ventilation duration, $\mathrm{d}$ & $61(29-358)$ & $37.5(21-301)$ & $40(21-168)$ & $708.5(63-3494)$ \\
\hline Mechanical ventilation duration already $\geq 90 \mathrm{~d}$ on study day, $\%$ & $18(29.5)$ & $4(11.1)$ & $6(15.0)$ & $17(85)$ \\
\hline \multicolumn{5}{|l|}{$\begin{array}{l}\text { ARDS }=\text { acute respiratory distress syndrome } \\
\text { APACHE }=\text { Acute Physiology and Chronic Health Evaluation } \\
\text { ICU }=\text { intensive care unit } \\
\text { VAP }=\text { ventilator-associated pneumonia }\end{array}$} \\
\hline
\end{tabular}

resources. Even with a high ratio of ICU staff, only a small portion of subjects could be weaned in the following 28 ICU days. Younger subjects, ARDS PMV patients, with fewer pre-morbid diseases were more prone to be successfully weaned. The optimal venue for taking care of patients requiring PMV needs to be investigated.

\section{ACKNOWLEDGMENTS}

Jie Li, Qingyuan Zhan and Chen Wang conceived and designed the study, Qingyuan Zhan and Chen Wang organized the Chinese prolonged mechanical ventilation study group, and the group members collected data. Jie Li analyzed and interpreted the data, and wrote the manuscript; Qingyuan Zhan and Chen Wang provided critical revisions and approved the final version of the manuscript. Jie Li is responsible for the entire manuscript.

The Chinese prolonged mechanical ventilation study group (Co-investigators and Study Coordinators):

Jie Li, Qingyuan Zhan, and Chen Wang were at Beijing Chaoyang Hospital when the study was implemented; Jie Li, Qingyuan Zhan, Chen Wang, Xiukai Chen, Wenxiong Li, Zhixin Cao (Beijing Chaoyang Hospital of Capital Medical University); Li Yi (Beijing China-Japan Friendship Hospital); Zongan Liang, Yongfang Zhou, and Yan Kang (West China Hospital, Sichuan University); Guojun He, Qibin Pu, Qiang Fang
(First Hospital of Zhejiang University); Tiancha Wang, Wei Cui (Second Hospital of Zhejiang University); Kailiang Duan, Huiqing Ge, and Yuehua Yuan (Sir Run Run Show Hospital of Zhejiang University); Ran Zhu, Xiaochun Ma (First Hospital of China Medical University); Sicheng Xu (First Hospital of Xinjiang Medical University); Qi Zhang, Li Jiang (Beijing Fuxing Hospital of Capital Medical University); Qianghong Xu (Zhejiang Hospital); Xiaoting Xu, Haibo Qiu (Nanjing Zhongda Hospital); Qixing Wang, Xiangyu Zhang (Shanghai No.10 Hospital of Tongji Medical University); Xiaofeng Xu (Beijing Anzhen Hospital); Jie Zhuo, Yuan Xu (Beijing Tongren Hospital of Capital Medical University); Zongyu Wang, Xi Zhu (Third Hospital of Beijing University); Zhonghua Shi (Beijing Tiantan Hospital); Shizhong Han (Dalian Central Hospital); Jiuzhi Zhang, Xianyao Wan (First Hospital of Dalian Medical University); Fen Zhou (Fujian Provincial Hospital); Shouhong Wang, Tiehe Qin (Guangdong Provincial Hospital); Lei Jiang, Minyan Zhao (First Hospital of Haerbin Medical University); Hongliang Wang, Kaijiang Yu (Second Hospital of Haerbin Medical University); $\mathrm{Na} \mathrm{Li}$, Zhenyang He (Hainan Provincial Hospital); Xixin Yan (Second Hospital of Hebei Medical University); Lixia Liu (Fourth Hospital of Hebei Medical University); Chuanyun Qian (First Hospital of Yunnan Medical University); Hong Guo (First Hospital of Lanzhou Medical University); Zhihui Tong (Nanjing Military Hospital); Xiyuan Xu (Third Hospital of Neimeng Medical University); Xudong Han (Third Hospital of Nantong Medical University); Feng Li (First Hospital of Nantong Medical University); Xigang Ma (First Hospital of Ningxia Medical University); Dan Hu (Qingdao Hos- 


\section{Survey of Prolonged Mechanical Ventilation in the ICU}

pital); Chen Li (Qilu Hospital of Shandong University); Hongsheng Ren (Shandong Provincial Hospital); Wei Chen, Enqiang Mao (Ruijin Hospital of Fudan University); Li Ma, Youzhong An (Beijing Renming Hospital of Beijing University); Zhihong Shi (First Hospital of Xi' an Jiaotong University); Xia Cao (Wuhan Renming Hospital of Tongji University); Bin Wu (Xiamen Third Hospital); Hongmin Wang (First Hospital of Zhengzhou Medical University); Cuizhu Luo, Yuhang Ai (Xiangya Hospital of Central South University); Daoxin Wang (Second Hospital of Chongqing Medical University); Yushan Wang (Second Hospital of Jilin University); Suocheng Tian (Liaocheng Hospital); Hong Chen (Beijing Xuanwu Hospital of Capital Medical University.)

\section{REFERENCES}

1. MacIntyre NR, Epstein SK, Carson S, Scheinhorn D, Christopher K, Muldoon S. Management of patients requiring prolonged mechanical ventilation. Report of a NAMDRC consensus conference. Chest 2005; 128(6):3937-3954.

2. Loss SH, Marchese CB, Boniatti MM, Wawrzeniak IC, Oliveira RP, Nunes LN, et al. Prediction of chronic critical illness in a general intensive care unit. Rev Assoc Med Bras 2013;59(3):241-247.

3. Lone NI, Walsh TS. Prolonged mechanical ventilation in critically ill patients: epidemiology, outcomes and modelling the potential cost consequences of establishing a regional weaning unit. Critical Care 2011;15:R102.

4. Hung TC, Lai YF, Tseng CW, Hong YH, Shi HY. Trend analysis of hospital resource utilization for prolonged mechanical ventilation patients in Taiwan: a population based study. Respir Care 2013; 58(4):669-675.

5. Cox CE, Carson SS, Holmes GM, Howard A, Carey TS. Increase in tracheostomy for prolonged mechanical ventilation in North Carolina, 1993-2002. Crit Care Med 2004;32(11):2219-2226.

6. Zilberberg MD, de Wit M, Pirone JR, Shorr AF. Growth in adult prolonged acute mechanical ventilation: implications for healthcare delivery. Crit Care Med 2008;36(5):1451-1455.

7. Kahn JM, Le T, Angus DC, Cox CE, Hough CL, White DB, et al. The epidemiology of chronic critical illness in the United States. Crit Care Med 2015;43(2):282-287.

8. Donahoe MP. Current venues of care and related costs for the chronically critically ill. Respir Care 2012;57(6):867-886; discussion 886-8.

9. Cox CE, Carson SS, Govert JA, Chelluri L, Sanders GD. An economic evaluation of prolonged mechanical ventilation. Crit Care Med 2007;35(8):1918-1927.

10. Damuth E, Mitchell JA. Bartock JL, Roberts BW, Trzeciak S. Longterm survival of critically ill patients treated with prolonged mechanical ventilation: a systematic review and meta-analysis Lancet Respir Med 2015;3(7):544-553.

11. Hough CL, Caldwell ES, Cox CE, Douglas IS, Kahn JM, White DB, et al. Development and validation of a mortality prediction model for patients receiving $14 \mathrm{~d}$ of mechanical ventilation. Crit Care Med 2015;43(11):2339-2345.

12. Lu HM, Chen L, Wang JD, Hung MC, Lin MS, Yan YH, et al. Outcomes of prolonged mechanical ventilation: a discrimination model based on longitudinal health insurance and death certificate data. BMC Health Serv Res 2012;12:100.
13. Scheinhorn DJ, Hassenpflug MS, Votto JJ, Chao DC, Epstein SK, Doig GS, et al. Post-ICU mechanical ventilation at 23 long-term care hospitals. A multicenter outcomes study. Chest 2007;131(1):85-93.

14. Lin MS, Yan YH, Wang JD, Lu HM, Chen L, Hung MC, et al. Improved survival for an integrated system of reduced intensive respiratory care for patients requiring prolonged mechanical ventilation. Respir Care 2013;58(3):517-524

15. Scheinhorn DJ, Hassenpflug MS, Votto JJ, Chao DC, Epstein SK, Doig GS, et al. Ventilator-dependent survivors of catastrophic illness transferred to 23 long-term care hospitals for weaning from prolonged mechanical ventilation. Chest 2007;131(1):76-84.

16. Liu CJ, Chu CC, Chen W, Cheng WE, Shih CM, et al. Impact of Taiwan's integrated prospective payment program on prolonged mechanical ventilation: a six-year nationwide study. Respir Care 2013; 58(4):676-682.

17. Polverino E, Nava S, Ferrer M, Ceriana P, Clini E, Spada E, et al Patients' characterization, hospital course and clinical outcomes in five Italian respiratory intensive care units. Intensive Care Med 2010; 36(1):137-142

18. Carson SS. Definitions and epidemiology of the chronically critically ill. Respir Care 2012;57(6):848-856; discussion 856-8.

19. Koenig SM, Truwit JD. Ventilator-associated pneumonia: diagnosis, treatment and prevention. Clin Microbiol Rev 2006;19(4):637-657.

20. Pilcher DV, Bailey MJ, Treacher DF, Hamid S, Williams AJ, Davidson AC. Outcomes, cost and long term survival of patients referred to a regional weaning centre. Thorax 2005;60(3):187-192.

21. Barchfeld T, Dellweg D, Böckling S, Conze S, Kloske K, Schürholz $\mathrm{G}$, et al. Weaning from long-term mechanical ventilation: Data of a single weaning center from 2007 to 2011. Dtsch Med Wochenschr 2014;139(11):527-533.

22. Robson V, Poynter J, Lawler PG, Baudouin SV. The need for a regional weaning centre, a one-year survey of intensive care weaning delay in the Northern Region of England. Anaesthesia 2003;58(2): 161-165.

23. Carson SS, Garrett J, Hanson LC, Lanier J, Govert J, Brake MC, Landucci DL, Cox CE, Carey TS. A prognostic model for one-year mortality in patients requiring prolonged mechanical ventilation. Crit Care Med 2008;36(7):2061-2069.

24. Li J, Zhan QY, Liang ZA, Tu ML, Sun B, Yao XL, et al. Respiratory care practices and requirements for respiratory therapists in Beijing intensive care units. Respir Care 2012;57(3):370-376.

25. Dermot Frengley J, Sansone GR, Shakya K, Kaner RJ. Prolonged mechanical ventilation in 540 seriously ill older adults: effects of increasing age on clinical outcomes and survival. J Am Geriatr Soc 2014;62(1):1-9.

26. Feng XW, Zhou XM, Qu WX, Li Y, Li SY, Zhao L. Retrospective analysis of related factors for patients with weaning difficulties in medical intensive care unit. Zhonghua Yi Xue Za Zhi 2011;91(38): 2688-2691.

27. Routsi C, Stanopoulos I, Zakynthinos E, et al. Nitroglycerin can facilitate weaning of difficult-to-wean chronic obstructive pulmonary disease patients: a prospective interventional non-randomized study. Crit Care 2010;14(6):R204. 